\section{Mulher, Medicina e tecnologia nos discursos de residentes em Obstetrícia/Ginecologia}

\author{
Women, Medicine, and technology in the discourse \\ of medical residents in Obstetrics/Gynecology
}

\author{
1 Instituto Fernandes \\ Figueira, Fundação Oswaldo \\ Cruz, Rio de Janeiro, Brasil. \\ Correspondência \\ A. C. B. Gilbert \\ Programa de Pós-graduação \\ em Saúde da Criança e da \\ Mulher, Instituto Fernandes \\ Figueira, Fundação \\ Oswaldo Cruz. \\ Av. Rui Barbosa 716 \\ Rio de Janeiro, $R J$ \\ 22250-020, Brasil. \\ ana.gilbert@terra.com.br
}

\section{Abstract}

This study focused on revealing the cultural meanings assigned to womanhood and the health-disease process in women according to the discourse of medical residents in Obstetrics/Gynecology at the Fernandes Figueira Institute, a public reference hospital specializing in maternal-child care in Rio de Janeiro. The research had two components: participatory observation in $\mathrm{Ob}$-Gyn meetings and recording of oral sources. The sign-based method was used to analyze the data. The methodology included qualitative analytical coding of interviews and subsequent semiotic analysis. According to the results: (a) women are seen essentially as mothers, and their illness focuses primarily on their childbearing function; (b) technological evolution, mainly with the increased use of imaging, has reduced the importance of semiology; and (c) within the biotechnological context medicalization is part of the material and semiotic practices.

Women's Health; Obstetrics; Gynecology
Ana Cristina Bohrer Gilbert 1

Maria Helena Cabral de Almeida Cardoso 1 Susana Maciel Wuillaume 1

\section{Introdução}

A sociedade é caracterizada por representações compartilhadas por homens e mulheres e que servem para firmar o seu pertencimento a ela. Socializar-se significa incorporar essas significações comuns marcantes da particularidade daquela sociedade específica 1 . Médicos e pacientes são partícipes desse processo e reproduzem valores, crenças, preconceitos que permeiam um determinado contexto sócio-cultural, podendo contribuir para cristalizar e/ou ressignificar estigmas 2 .

Por sua vez, a cultura é como uma lente através da qual se olha o mundo e é multifocal, porque não existe a cultura, mas culturas relativas à variedade dos grupos humanos e seus contextos históricos. A cultura é uma gramática que gera os elementos que a constituem, estabelecendo significados aos mesmos e às suas relações ${ }^{3}$. A base de conhecimentos e práticas da Medicina está estreitamente articulada à cultura, da mesma forma como a história que o paciente constrói sobre sua doença, os sentidos a ela atribuídos, ao seu corpo e ao seu sofrimento.

Versões feministas sobre objetividade argumentam não ser possível discutir ciência assumindo uma posição universal, pois esta se descola de um determinado contexto; ao invés de uma visão única de ciência, pugnam por perspectivas particulares, conhecimentos localiza- 
dos, críticos e responsáveis, sustentando a possibilidade de estabelecer redes de conexões 4.

A noção de conhecimentos localizados contrasta enormemente com o conceito de "vida em si”, um tipo de literalismo que permeia o discurso da ciência, buscando fixar as relações dinâmicas entre natureza e cultura e que a faz acreditar-se livre de toda linguagem figurada, a-histórica e descontextualizada.

Foi assumindo esse tipo de postura que este estudo voltou-se para dois temas caros ao campo da saúde coletiva: saúde da mulher e formação médica.

A saúde da mulher constitui um dos focos de política pública brasileira, pautada no conceito de integralidade da assistência, objetivando oferecer atividades de assistência clínica e educativa, que abarquem não só o período reprodutivo, pré-natal, parto e puerpério, mas também outros problemas desde a adolescência até a terceira idade, passando pelas doenças sexualmente transmissíveis, o câncer cérvico-uterino e mamário, a concepção e a contracepção 5 .

A identificação dos significados culturais que impregnam os discursos médicos dos profissionais ainda em formação é fundamental à compreensão do efeito de determinadas ações e à possibilidade de redirecionamento das mesmas, no sentido de torná-las mais eficazes.

Mudanças culturais não ocorrem em curto prazo. A reorientação da prática em direção a uma maior integralidade no atendimento está permeada por questões mais profundas, como os valores culturais arraigadamente presentes nos profissionais e implícitos nos contatos realizados com suas pacientes, acerca de seus corpos e seu processo de adoecimento.

Por isso, no que tange à formação médica, optou-se por trabalhar com a residência, por essa ser uma modalidade de ensino de pós-graduação, voltada para profissionais visando a uma especialização, conjugando ensino e assistência, o que significa que tais profissionais são ainda alunos em processo de constituição de uma identidade profissional, de um discurso sobre suas pacientes e de aprimoramento do raciocínio clínico. A coexistência desse duplo papel comporta uma série de ambigüidades, dúvidas e inseguranças, com relação à definição da Medicina como ciência, cujo objeto de estudo é a doença, e como arte, relativa à clínica, que lida com as singularidades das pacientes, que não se adapta totalmente à teoria geral das doenças e que valoriza a experiência.

\section{Construção e análise das fontes}

Optou-se por um estudo de caso institucional 6 com residentes dos Serviços de Obstetrícia/Ginecologia do Instituto Fernandes Figueira (IFF), da Fundação Oswaldo Cruz (FIOCRUZ), que concluíram a Residência Médica em janeiro de 2004. A pesquisa constou de duas etapas: a primeira, um período de observação participante em quatro reuniões da Ginecologia e em quatro da Obstetrícia, com o objetivo de recolher dados para subsidiar a construção de fontes orais. O material recolhido foi registrado sob a forma de notas de campo.

A segunda etapa seguiu o método para construção de fontes orais, elaborado e testado por Cardoso 7, composto de quatro módulos articulados e interdependentes de entrevistas, trabalhando três tipos entrelaçados de memória: a individual, expressão de desejos, aspirações e conflitos; a coletiva, como forma de experiência de um grupo e a histórica, como recordação dos fatos no mundo. O método propõe colher depoimentos pessoais, nos quais cada entrevistado responde sobre sua vida e visão de mundo, numa atitude autobiográfica que organiza as lembranças, o labirinto das memórias 8 , para romper com os limites individuais e pontuais e acessar informações pertencentes aos contextos sócio-históricos mais amplos.

Foram entrevistados sete médicos, cinco mulheres e dois homens. A oitava residente não participou, pois estava de licença médica.

A análise semiótica dos depoimentos considerou que todo enunciado, verbal ou não, é dotado de significação e funções integrais, compondo um texto. Foram observados elementos como coerência textual, competência textual e intertextual, estruturas superficiais e profundas do texto e o processo de "discursivização", compreendendo a "actorialização" (como se instituem os personagens), "temporalização e espacialização" (como aparecem os efeitos do tempo e do espaço), "tematização" (como se dá a geração dos elementos abstratos) e "figurativização" (o aparecimento dos elementos concretos) 9 .

Os resultados foram trazidos entrelaçados à discussão teórica. Por questões de limite de espaço, foram exemplificados por frases proferidas pelos residentes, escolhidas dentre aquelas que refletem a posição geral. O percurso foi o de apontar um tópico relevante trazido pelos entrevistados, discuti-lo teoricamente e ilustrá-lo.

$\mathrm{O}$ artigo centra-se nas experiências vividas nos dois anos de residência médica, privilegiando as concepções sobre a mulher e a formação especializada de atendimento que a en- 
volve, tendo sido o projeto de pesquisa que o embasou aprovado pelo Comitê de Ética em Pesquisa do IFF/FIOCRUZ, sob o parecer n. 054/03, de 4 de dezembro de 2003.

\section{Saúde da mulher: a imagem da mãe}

A análise dos depoimentos revelou claramente a percepção de mulher como qualificada e/ou definida pelo atributo de ser mãe. Nas sete entrevistas, a força dessa delimitação levou ao empreendimento de um esforço contextual para que a historicidade dessa imagem não se perdesse numa mera constatação. Observouse a instituição do personagem mãe/mulher; a circunscrição espaço/temporal da capacidade reprodutiva como chave ao estabelecimento de períodos definidos de evolução dos corpos femininos; a tematização da essência feminina como nutriz, cuidadora, gestora da família; o surgimento de elementos figurativos como "dona-de-casa", "seio", "bebês", "filhos", "marido", "esposa”, "mulher/mãe/profissional”, tendo como contraposição a eles as mulheres "nervosa", "promíscua", a "mãe/adolescente", dentre outros. São esses os aspectos maciçamente enunciados, que serviram de fio condutor à discussão que se segue.

Em nossa cultura, masculino e feminino foram reduzidos a estereótipos de homem e mulher, fixando atributos e cristalizando comportamentos. Entretanto, eles podem ser entendidos, em termos psicológicos arquetípicos, como temas presentes nas diversas mitologias humanas, como nas representações dos deuses gregos, ou na filosofia chinesa, sob a forma de yin (feminino) e yang (masculino).

Dentro desse enfoque, é possível vincular seus significados a aspectos biológicos, atribuindo ao masculino, e não exclusivamente ao homem, elementos como atividade, agressividade, competição, linearidade, luminosidade e intelecto; e ao feminino, e não exclusivamente à mulher, a receptividade, a passividade, o cuidado, o cíclico e o obscuro, todos eles presentes e necessários à psique humana. Tal entendimento também é fruto de uma construção cultural e, como tal, constitui uma perspectiva parcial e limitada.

Os trabalhos que abordam gênero e suas conexões com sexualidade e corpo e que se referem às diferenças entre homem e mulher não costumam coadunar com o entendimento de masculino e feminino como temas mais amplos; voltam-se para as implicações valorativas que tais conceitos adquirem quando localizados em corpos de homens e mulheres, e para a discussão da naturalização/construção de suas diferenças. Assim, são várias as vertentes desenvolvidas por biólogos, antropólogos, sociólogos, historiadores e cientistas políticos para estudar o assunto.

Uma delas, de tipo funcionalista, enfatiza a marcação biológica das diferenças, sejam elas morfológicas, neuronais, hormonais ou genéticas, salientando certo determinismo: o homem possui naturalmente um temperamento de caçador, competitivo, lutador, enquanto a mulher se apresenta naturalmente cuidadora e cooperativa; ela é aprisionada numa função reprodutiva biológica, enquanto ele se torna o agente dos processos sociais 10 .

Outra entende gênero não como algo inato, mas como um conceito relacional, construído e negociado socialmente, sofrendo alterações e resistências. Esses enfoques privilegiam a polaridade que cria categorias separadas como natureza/cultura, sexo/gênero, defendendo que o modelo social da heterossexualidade foi o determinante na histórica opressão da mulher pelo homem 4 .

E uma terceira discute a existência de algo na concepção de gênero que extrapola idéias e conceitos abstratos, da interação entre as pessoas e que está impregnado no corpo. Cassell 11 (p. 39) utiliza o conceito dialético de habitus de Bourdieu, como uma "estrutura social corporificada" que estabelece formas de percepção e gera práticas e representações. É mais do que pensamento racional; é parte constitutiva da pessoa, alicerçada nas ações e reações do seu corpo. O que é assimilado dessa forma independe das palavras e acontece muito precocemente; ganha significado e valores. Permite que o corpo de uma pessoa perceba o corpo de outra, ainda que de forma intuitiva e sem conseguir traduzir em palavras, determinando padrões de comportamento e formas de agir, reagir e julgar.

Trazer a discussão de gênero para o campo da Obstetrícia e da Ginecologia, aqui representado pelos residentes, é perceber quais os alicerces das diferenças sexuais e de gênero presentes no olhar sobre a paciente e as repercussões que podem suscitar nos atendimentos. É apontar que, nos depoimentos analisados, as duas primeiras correntes misturam-se, mas com certa predominância da primeira.

Todos os entrevistados apontam para uma conquista muito grande por parte da mulher em termos de espaço, de realização, de liberdade e de autonomia, mas que é permeada por padrões antigos conflitantes. Essa nova posição aparece de forma mais ou menos implícita e corresponde a uma mulher ainda reticente 
diante de certas responsabilidades, presa a um único papel predominante. Conforme diz um deles sintetizando os demais: "É de ser meio pára-raios, o centro da família, aquela coisa do seio (...). Ainda é assim: a coisa da mãe".

A divisão sexual do trabalho, implicando nos modelos tradicionais de homem e mulher, prevalece nos depoimentos como inerentes à condição humana. As conquistas alcançadas pela mulher soam como somatório, cabendo a ela a responsabilidade da casa e a educação dos filhos, mesmo quando essas tarefas podem ser negociadas.

A preponderância desse papel corresponde a uma visão de família como instituição universal, cuja unidade é composta por pai, mãe e filhos, ou apenas por mãe e filhos. Fonte natural de nutrição preenche as necessidades humanas de sobrevivência (alimentação, vestuário e abrigo), e as necessidades psicológicas de relação (afeto, cooperação e estabilidade). Possui limites claros, possibilitando uma diferenciação de outras unidades, a demarcação espacial do lar e a manutenção de vínculos emocionais 10 .

Essa família emerge com o Estado Moderno, encaixando-se na dicotomia público/privado e reforçando as polaridades: impessoal/ pessoal, trabalho/lazer, consumo/produção e criando uma zona denominada "vida pessoal", à qual se conecta a identidade sexual e que, supostamente, localiza a sexualidade como algo exclusivo do indivíduo 12.

Barthes 13, ao estudar os mitos contemporâneos presentes na sociedade burguesa francesa, afirma que tudo é passível de ser transformado em mito, desde que enunciado por um discurso. O mito se apresenta como uma fala despolitizada, despojando o objeto de sua história, cuja eficácia reside na naturalização da fala, transformando algo contextualizado em universal.

Na referência à mulher-mãe, presente no verbalizado por todos os entrevistados, observa-se o mito barthiano, eliminando todo o caráter histórico do ser mulher por eternizá-la numa determinada imagem.

Ser mãe é o aspecto principal da natureza da mulher, conforme o difundido no século XIX, quando a Medicina higienista estabeleceu "mapas de saúde" para guiar a família, inicialmente a burguesa, nas novas formas de convívio, demarcando os espaços de sociabilidade em vigência a partir de então. Esse modelo iguala homem e mulher às figuras de pai e mãe, respectivamente, estabelecendo padrões reguladores a serem seguidos no domínio da sexualidade 14. Para fixar esses modelos, realçou-se a conduta machista peculiar ao homem, assegurando sua dominação sobre a mulher; e à mulher, sua aliança com o poder médico, circunscrevendo sua sexualidade à estabilidade conjugal e responsabilidade com os filhos, originando a "mulher nervosa".

A histerização do corpo da mulher foi uma estratégia de saber e poder sobre o sexo, cujo dispositivo foi a exacerbação do conteúdo sexual no corpo da mulher, permitindo sua incorporação ao campo das práticas médicas, como intrinsecamente portador de doença e o estabelecimento das relações dessa mulher com o social, com a família e com a criação dos filhos através do componente orgânico 14.

Nessa ótica, a mulher utiliza-se do corpo adoecido e do sexo para reclamar seus direitos ou escapar às exigências familiares impostas pela higiene, e o médico manteria a sexualidade feminina sob controle através da medicalização 15.

Em todos os depoimentos, essa mulher ainda existe: ela aparece acompanhada do companheiro ou de parentes e, segundo os residentes, usa seus sintomas como uma simulação para obter atenção por parte da família e/ou do médico, ou para expressar sua insatisfação sexual e com a vida em geral, o que, muitas vezes, ela própria desconhece. É vista como quem não quer melhorar e costuma trazer uma queixa após a outra, desqualificando-se como doente. "Toda vez ela diz que está muito doente. Principalmente se vier acompanhada (...) Isso facilita para você saber se está fazendo drama ou não" são palavras que exemplificam bem essa posição.

Por outro lado, a predominância da função materna cria um pólo oposto que abarca tudo que se relaciona à sexualidade como exercício desvinculado do ser mãe, produzindo, além do estereótipo da mulher "histérica", o da mulher "promíscua".

A situação de mulheres que se encaixam nesse último aparece entre os residentes como difícil de lidar e envolve uma preocupação com o não julgamento que, entretanto, faz-se presente. "Não é que a gente trate diferente, mas você [pode] ter um olhar um pouco preconceituoso, às vezes, menos cuidadoso com uma paciente que tem uma vida promíscua", conforme declara um deles, respaldando a visão geral.

Aspectos polares tendem a exacerbar comportamentos e a classificá-los como certos ou errados. A mulher que apresenta comportamentos considerados promíscuos reforça a dualidade que contrapõe a mulher-mãe intocável à mulher-acessível que, em termos médicos, apresenta-se como risco, justificando a preo- 
cupação com sua vida sexual, seus parceiros e pautando a necessidade de orientação. Esta é tida como o instrumento para lidar com ela, contornando julgamentos morais percebidos como preconceituosos e subjetivos.

A sexualidade, segundo Foucault 14, equiparou-se a um segredo que, ao contrário de ser guardado, estimulou-se a ser confessado para atingir-se a verdade sobre o sexo. $\mathrm{O}$ autor questiona a tese de uma repressão crescente do sexo para falar de mecanismos geradores de poder e de uma vontade de saber, multiplicadores dos discursos sobre ele.

Dessa forma, o reconhecimento do próprio corpo pela burguesia significou a afirmação de sua consciência de classe. O corpo e a sexualidade sadios foram seus trunfos. Só mais tarde é que o proletariado pôde ser dotado de corpo e de sexualidade, quando surgiram conflitos e necessidades que tornaram imperiosas tais preocupações, o que também gerou a instauração de mecanismos de vigilância e controle desses corpos 14. A explicação foucaultiana encontra respaldo nos depoimentos, quando a preocupação com a informação, para tratar os temas sexuais que envolvem riscos, é considerada premente. Subjacente, nas vozes dos residentes, está a idéia de que essa permite o conhecimento do corpo, sendo a ferramenta mais adequada para propiciar mudanças de comportamento.

Lidar com pacientes consideradas de risco e assintomáticas implica, de acordo com os entrevistados, em outras dificuldades, tais como adotar medidas preventivas e direcioná-las a tomar certos cuidados, ainda que elas não se percebam potencialmente doentes 16 . O mesmo acontece com as adolescentes grávidas. A gestação na adolescência é considerada de risco, porque certas complicações têm maior incidência nesse período. Por não se sentirem doentes e acrescidas as características próprias da adolescência, como falta de maturidade, as adolescentes também são consideradas "difíceis". Elas são vistas como descuidadas e incapazes de encarar a chegada de um bebê com responsabilidade. As palavras que seguem exemplificam bem o pensamento comum: "[Elas] encaram [a gravidez] como brincar de boneca. Eu acho que tem que ter uma orientação maciça em relação a isso e ao parto, porque elas não toleram a dor do parto".

\section{Formação médica: o corpo e a doença}

O entendimento dos corpos femininos e das doenças manifestas nesses corpos, cuja "realidade” só é atingível pela mediação da tecnolo- gia, aparece nos depoimentos como o objeto per se da especialização. O conhecimento restrito a um órgão anatomicamente bem definido embasa todas as concepções verbalizadas, de modo que aquilo que escapa a esse território, para os depoentes, recai no espaço das queixas difusas, na maioria das vezes, por eles explicadas em função de frustrações e insatisfações psíquicas e sociais. Nesses casos, a tecnologia, principalmente a vinculada à imagem, transforma-se num instrumento delimitador dos encontros intersubjetivos, salientando-se como a base sobre a qual a argumentação que define o diagnóstico e a aceitação da terapêutica deve repousar.

A Obstetrícia/Ginecologia surge nos depoimentos como especialidade devidamente mapeada, na qual os avanços tecnológicos são responsáveis por aprimorar a visão, mais do que por trazer novas descobertas. Para os residentes, a imagem possibilita que o corpo, visto como mapa, seja cada vez mais conhecido, localizado, visualizado.

Mapas são aceitos como representações livres de linguagem figurada de algo real, absoluto, que "está lá" disponível para ser conhecido. Considerando-se o corpo da mulher como mapeado pelo olhar da Obstetrícia/Ginecologia, seria possível desvendar e acompanhar seus processos através de indicações precisas. Contudo, mapas não são apenas instrumentos, mas refletem práticas históricas multifacetadas 17, ou seja, eles são contextuais e moldados por relações de significado ao mesmo tempo em que as moldam.

Da mesma forma que, em certos trabalhos fotográficos, em especial a fotografia jornalística, acredita-se que o fotografado simplesmente estava lá e que a mensagem transmitida não contém nenhum código, o exame complementar, sobretudo por imagem, é entendido pelos entrevistados como uma revelação do real, apesar da constatação de sua condição pontual, na qual a dinâmica do processo é perdida. Traz segurança a eles e às pacientes; comprova, evidencia e, por isso, é priorizado em relação a outras fontes de informação consideradas menos confiáveis. Porém, assim como o ato fotográfico, o exame é circunstancial e depende não só do momento em que foi realizado, mas também de sua recepção e contemplação 18 .

Nas entrevistas, há priorização do funcionamento normal do corpo da mulher, e seus significados relacionam-se aos aspectos reprodutivos, dentro do modelo hierárquico orgânico. A emergência desse corpo como campo de forças, repleto de significados, não é possível para o médico, nem para a paciente. 
É difícil delimitar o que é normal quando os discursos do médico e da paciente se confrontam: o que é trazido pela história da paciente ao médico é o diferente, o que se apresenta como estranho a ela, fora do "seu padrão" e a torna vulnerável; para ele, quase sempre é algo conhecido, mapeado, estudado, passível de apresentar mais de um caminho a ser percorrido até sua solução. Como enfrentar esse descompasso? Como diz um deles, refletindo a posição dos demais: "Eu tento dizer: 'olha, seus exames estão normais', tento sinalizar que outras coisas podem estar fazendo ela se sentir mal".

Conforme afirmam os entrevistados, a mulher vem ao obstetra por uma questão pontual que é a gravidez. Já a vinda ao ginecologista envolve mais do que uma situação específica, abarcando aspectos de insatisfação de vida.

A mulher vem ao médico para que este a decifre, a interprete, a ajude a restituir o seu normal. E cobra dele que a entenda mais do que ela mesma é capaz. Nesse sentido, ela é um outro para si mesma, desconectada de seus processos internos, incapaz de contar sobre esse corpo, numa atitude "descorporificada", isto é, desconectada da experiência individual e contextual 12 .

No depoimento de uma residente, é possível notar isso, quando se refere a procedimentos cirúrgicos como solução para extirpar algo que não é a mulher, mas que se aloja nela. Não se pretende questionar a indicação dos procedimentos e sua validade, mas a atitude da paciente em relação aos seus órgãos, em estado "patológico", anormal. Conforme declara: “As pacientes com indicação cirúrgica de HTA [histerectomia], muitas [dizem]: 'Doutora, tira tudo, arranca fora!', até porque geralmente os sintomas são dor, sangramento, são coisas que incomodam muito".

Existe uma percepção clara, por parte dos residentes, do que pode ser considerado como doença, a partir de uma definição de lesão, coerente com o modelo morfológico, anatomopatológico, e um sentir-se doente que é trazido pela paciente e não necessariamente condizente com a definição de doença. Isso se refere tanto à intensidade das percepções que a mulher traz, relativas à dor ou ao desconforto (que podem ser, na visão do médico, adequados ou não ao caso), como também se referem aos incômodos cuja origem não é revelada no exame físico ou nos exames complementares. Esse se sentir doente vago adquire um ar de transcendência, que extrapola o âmbito da especialidade.

A Medicina baniu os aspectos mágicos que a constituíam e incorporou a essa dimensão os sintomas psicológicos. Dessa forma, o que é indecifrável (e talvez, para os residentes, insolúvel) deve ser encaminhado a quem detém os poderes que permitem entrar em contato com tais questões: o psicólogo e o psiquiatra, os representantes mais próximos do xamã. Permanece a dicotomia entre sofrimento orgânico e sofrimento psíquico, sendo esse último de menor importância e expressão de algo que não é "real" 19.

A "conversa", trazida pelos residentes como estratégia para lidar com o sofrimento psíquico, adquire um tom mágico, que irá resolver tais incômodos. O trecho a seguir reflete uma postura generalizada: "O que a gente tem que fazer é orientar para ela não se sentir doente; às vezes, conversando, para ela já é um tratamento".

As questões relativas à reprodução e aos papéis sexuais, assim como a outros aspectos da diversidade humana, não podem ficar restritas a aspectos orgânicos, tidos como essências naturais e saudáveis em organismos e famílias. Eles devem ser pensados em termos de campos de força de diferenças. Nesse sentido, não cabe uma oposição entre o orgânico, o tecnológico, o textual, o mítico, mas sim a noção de falha nesse sistema de comunicações, que, de alguma maneira, expressa-se no corpo 4 .

Winograd \& Flores 20 defendem a conexão entre o mundo externo e o interno, entre organismos, entre o orgânico e o tecnológico como sendo da ordem da metáfora e da comunicação, mas sempre inserida num contexto, no qual a linguagem se apresenta como algo construído e não natural.

De acordo com os autores, o sistema imunológico pode ser entendido como um "diagrama” das relações e uma orientação quanto à maneira de agir no tocante aos limites do eu e à mortalidade. Apresenta novas possibilidades diante de um mundo repleto de não-eu, de confronto com a diferença e onde a concepção do patológico é redesenhada fora do cenário da batalha. Dessa forma, o adoecimento pode ser visto como uma oportunidade que permite revelar quais as ferramentas usadas nas relações com o mundo.

As doenças são acompanhadas por metáforas construídas socialmente para ajudar a entender ou interpretar certos fenômenos do processo de adoecimento, mas que podem enrijecer o seu entendimento ou estigmatizar as pacientes.

A noção de risco costuma carrear metáforas, por exemplo, o referir-se como alto ou baixo querendo expressar mais ou menos, ou transformando-o em entidade corporificada que ameaça o indivíduo que a ele se expõe, permitindo-o ser objetivado e ter suas causas identificadas 16 . 
A análise dos depoimentos apontou que certos processos tornam-se eles mesmos metáforas capazes de adjetivar outros fenômenos, como a gestação e o parto, na Obstetrícia, entendidos como uma metáfora temporal (algo que é demorado e/ou difícil), e o câncer, na Ginecologia, como uma metáfora espacial, visto que o câncer pode alojar-se em qualquer órgão e "espalhar-se" (algo que consome e é negativo).

A metonímia é outro tropo que consiste em nomear um objeto por uma palavra designativa de outro objeto que tem com o primeiro uma relação de substituição da parte pelo todo 21 . Ela aparece com freqüência nos relatos dos depoentes, nos quais a mulher passa a ser nomeada pela enfermidade que apresenta, como, por exemplo, uma "dor pélvica", ou um "HTA".

Todos esses recursos lingüísticos estão presentes nas narrativas que as pessoas constroem sobre si e sobre o mundo. Narrar constitui algo que é muito antigo no homem, é a forma mais tradicional de relatar sua humanidade, aquilo que não pode ser medido ou quantificado, sendo considerada, muitas vezes, como antagônica à objetividade e à cientificidade 22 .

É inegável que paciente e médico compõem narrativas diferentes, pois um tem a experiência vivida do adoecimento; o outro tem a experiência do saber sobre aquele processo e de tê-lo visto em outro momento, ainda que poucas vezes. Essa diferença existe mesmo quando ambos provêm de um mesmo contexto cultural. As histórias contadas pela paciente e as histórias elaboradas pelo médico são versões distintas da mesma doença. Entretanto, existe um movimento de ambos no sentido de contornar tais diferenças: a paciente incorpora algo do jargão médico ao expressar seu desconforto, e o médico tenta trazer seu conhecimento e sua orientação para uma linguagem que possa ser familiar à paciente 22 .

O estudo da semiologia médica, essencial ao desenvolvimento do raciocínio clínico, capacita o aluno de Medicina, a partir do terceiro ano da graduação, a obter informações de seus pacientes, através da anamnese. É a partir dessa anamnese que a narrativa médica vai sendo delineada, com a inclusão de informações relevantes que dizem respeito às condições fisiológicas da paciente, mas que se revela muito importante na percepção de componentes contextuais do adoecer dela 22. O corpo mostra ser mais do que sua faceta fisiológica; ele é também depositário cultural de expectativas e significados sociais e ideológicos 23 .

A fascinação que a tecnologia dos exames complementares exerce, trazendo mais segurança para a elaboração do diagnóstico, com seus métodos cada vez menos invasivos, determina que certas averiguações percam importância diante da possibilidade da imagem mostrar mais, com mais segurança e menos esforço, sem exigir uma sensibilidade mais aguçada por parte do médico. Percebe-se uma tendência a um distanciamento do eixo semiológico da Medicina, como percurso indiciário de interpretação de sinais e sintomas, no qual o narrar é fundamental. A disponibilidade cada vez maior de exames, gerando uma grande quantidade de informação, traz o risco de obtenção de resultados discordantes e de perda do real sentido da sua solicitação.

\section{Considerações finais}

Ao discutir-se a saúde da mulher com a medicalização de seu corpo, processo que começou a partir do século XIX e que continua até hoje, é necessário que se considere a impossibilidade de um corpo autêntico, genuíno, dissociado do discurso e das práticas médicas e biotecnológicas, para pensar corpos entendidos e assimilados de várias maneiras, de acordo com a "lente" através da qual estão sendo vistos.

A medicalização se refere às relações entre poder, conhecimento médico, prática clínica e o encontro médico-paciente. Provê a paciente com indicações sobre como se relacionar com seu corpo, aprimorá-lo, regulá-lo, com vistas à promoção da saúde, da produtividade e, em última instância, à manutenção da ordem social 24. Para os residentes entrevistados, a Obstetrícia e a Ginecologia são vistas como especialidades que trabalham primordialmente sob um enfoque informativo, no sentido de convencer as mulheres a seguirem determinados cuidados com o próprio o corpo, a fim de prevenir estilos de vida que as põem em risco de adoecer.

A falta de conhecimento teórico-técnico das pacientes, sublinhada em todos os depoimentos, evidencia o entendimento da existência de um desnível entre elas e o médico, tornando-as vulneráveis diante das decisões tomadas por ele, com pouca possibilidade de questionamento. Isso é agravado em populações consideradas menos favorecidas, como a atendida no IFF, que não se encontram em situação de enfrentar essa relação assimétrica. Assim, a incorporação das informações biomédicas é entendida por todos como uma ferramenta basal no processo de mudança do status quo e, conseqüentemente, uma vitória no caminho mais da prevenção das enfermidades do que da promoção à saúde. 
Visões como essas estão no centro de muitos estudos feministas críticos do processo de medicalização, que a reduzem a uma forma de manter a dominação e o controle masculinos sobre os corpos das mulheres, estimulando uma alienação em relação ao seu funcionamento e dificultando o resgate e a integração dos mesmos em termos de identidade e sexualidade 25 .

Contudo, essa posição também apresenta lacunas, pois não abarca a complexidade da questão e mantém a polaridade na qual os médicos são apontados como dominadores, voltados exclusivamente para o exercício do poder, e as pacientes, como passivas, vitimizadas, totalmente desprovidas de qualquer tipo de poder 26 .

Entretanto, o que a análise apontou é que parece existir uma cumplicidade na manutenção de determinados padrões, envolta em sentimentos contraditórios de aceitação, rejeição e questionamento, e que reproduzem a dominação médica.

Por outro lado, a ênfase no monitoramento dos órgãos reprodutivos na mulher, seja em estado gravídico ou não, numa afirmação da imagem da mulher-mãe, permite o desvendamento de territórios antes envoltos em opacidade. A visualização, como ato predominantemente masculino comum a homens e mulheres por ser hegemônica e universal, remete ao controle histórico do homem sobre a ciência, às imagens evocativas da batalha, da conquista e do domínio 27 , e à oposição entre visão e toque, ou entre corporificado e incorpóreo 4.

A grande inserção da tecnologia na Medicina que tinge o discurso de todos os entrevistados, tanto nas áreas de pesquisa quanto na prática diária da clínica, da cirurgia, dos exames, é vista menos como mediadora das relações entre médicos e pacientes e mais como elemento que possibilita um distanciamento dos conflitos que permeiam essas relações, em direção a domínios nos quais o humano perde visibilidade.

Nesse sentido, os sete residentes entrevistados parecem ainda estar mergulhados no que o Dr. Jerry Vannatta, ex-reitor da Escola de Medicina da Universidade de Oklahoma, refere como sendo uma religião dentro da comunidade médica. Essa religião, difundida ao longo de todo o processo de educação e formação médicas, implica na crença de que a tecnologia será capaz de fornecer as evidências à formulação do diagnóstico, quando já se sabe que, ainda no século XXI, em 80 a $85 \%$ dos casos, esse continuará a ser feito com base na história do paciente 28 . Estudos recentes vêm confirmando a importância da competência narrativa, entendida aqui como ferramenta de tecnologia leve 29 , não apenas no que se refere à construção do diagnóstico, mas à possibilidade de melhor articular ciência e arte, teoria e prática, exercício esse tão cheio de dúvidas e inseguranças para os residentes. Tal competência se relaciona também à capacidade fundamental de escutar uma história e de narrar o que se está percebendo, elementos primordiais do encontro médico-paciente e imprescindíveis a uma assistência mais humanizada 30 .

O momento do encontro do médico com a paciente, vista fundamentalmente como mãe, traduz-se em instabilidade quando o não revelado e o que extrapola a função materna prevalecem. O corpo deixa, então, de ser um conceito de localização geográfica para transformarse em uma complexa rede de relações e significados, quase sempre inacessível para ambos.

Uma forma de entender a medicalização tal como se apresenta hoje, imersa num contexto no qual a tecnologia é parte integrante, extrapola as posições cristalizadas e polarizadas de progresso ou de retrocesso. Talvez a solução resida, tanto para os médicos quanto para as mulheres que atendem, em considerá-la como metáfora em dois aspectos: como entendimento de que todos os processos humanos de saúde e doença são mediados por alguma intervenção tecnológica, desde a mais simples até a mais sofisticada, não sendo possível pensar qualquer um deles sem absolutamente nenhuma mediação; e como testemunha dos atuais avanços tecnobiocientíficos, com seus sucessos e seus fracassos; seus riscos e seus benefícios 31 .

Refletir sobre essa perspectiva implica não apenas em assimilar os avanços e as possibilidades de aplicação das últimas descobertas tecnológicas, mas questionar acerca da posição que cada pessoa/profissional ocupa, seu engajamento e sua responsabilidade e o risco que isso representa; e das profundas mudanças que acarretam nas teias de relações entre humanos, não humanos e suas culturas. 


\section{Resumo}

Este estudo objetivou explicitar os significados culturais sobre a mulher e seu processo de adoecimento que estão presentes nos discursos médicos de residentes em Obstetrícia/Ginecologia do Instituto Fernandes Figueira, Fundação Oswaldo Cruz. A pesquisa foi realizada em duas etapas: observação participante e construção de fontes orais. Tendo como referência o modelo indiciário, o procedimento técnico-metodológico utilizado incluiu uma codificação analítica qualitativa das entrevistas e posterior análise semiótica. Os resultados apontam para: (a) a percepção da mulher como essencialmente mãe, cujo processo de adoecimento é focado prioritariamente em sua função reprodutiva; (b) o crescente aumento do uso de tecnologia, sobretudo nos exames por imagem, provocando um distanciamento do eixo semiológico da Medicina; $e$ (c) a medicalização, inserida no contexto biotecnológico, como envolvendo práticas materiais-semióticas.

Saúde da Mulher; Obstetrícia; Ginecologia

\section{Referências}

1. Augusto MHO. Tempo e indivíduo no mundo contemporâneo: o sentido da morte. Psicol USP 1994; 5:157-72.

2. Martins AJ, Cardoso MHCA, Llerena Jr. JC. Em contato com as doenças genéticas. A norma e a razão como tradições culturais presentes no discurso de profissionais médicos do Instituto Fernandes Figueira, Fundação Oswaldo Cruz. Cad Saúde Pública 2004; 20:968-75.

3. Rodrigues JC. Antropologia e comunicação: princípios radicais. Rio de Janeiro: Editora Espaço e Tempo; 1989.

4. Haraway D. Simians, cyborgs, and women. The reinvention of nature. New York: Routledge; 1991.

5. Ministério da Saúde. Assistência integral à saúde da mulher: bases de ação programática. Brasília: Ministério da Saúde; 1984.

6. Yin RK. Case study research. Design and methods (applied social research methods). London: Sage Publications; 2002.

7. Cardoso MHCA. Programa de história oral: os quatro módulos. Método e prática. História em Cadernos 1986; 4:29-35.

8. Feitosa C. Labirintos: corpo e memória nos textos autobiográficos de Nietzsche. In: Lins D, Gadelha S, organizadores. Nietzsche e Deleuze. Que pode o corpo. Rio de Janeiro: Relume-Dumará; 2002. p. 49-66.

9. Cardoso CF. Narrativa, sentido, história. Campinas: Papirus Editora; 1997.

10. Collier J, Rosaldo MZ, Yanagisako S. Is there family? New anthropological views. In: Lancaster RN, Di Leonardo M, editors. The gender sexuality reader. New York/London: Routledge; 1997. p. $71-81$.

\section{Colaboradores}

A. C. B. Gilbert contribuiu com a coleta e a análise dos dados e a redação do artigo. M. H. C. A. Cardoso colaborou na análise dos dados, na redação e revisão do artigo. S. M. Wuillaume participou na redação e revisão do artigo.

11. Cassell J. The woman in the surgeon's body. Cambridge: Harvard University Press; 2000.

12. Ross E, Rapp R. Sex and society. In: Lancaster RN, Di Leonardo M, editors. The gender sexuality reader. New York/London: Routledge; 1997. p. 153-68.

13. Barthes R. Mitologias. Rio de Janeiro: Bertrand Brasil; 2001.

14. Foucault M. História da sexualidade. A vontade de saber. v. 1. Rio de Janeiro: Graal; 2003.

15. Costa JF. Ordem médica e norma familiar. Rio de Janeiro: Edições Graal; 1999.

16. Castiel LD. Moléculas, moléstias, metáforas. O senso dos humores. São Paulo: Unimarco Editora; 1996.

17. Haraway D. Modest_Witness@Second_Millenium. FemaleMan@_Meets_OncoMouse ${ }^{\mathrm{TM}}$. New York: Routledge; 1997.

18. Dubois P. O ato fotográfico e outros ensaios. Campinas: Papirus Editora; 1994.

19. Castoldi MA. Tornar-se pediatra. O desenvolvimento do raciocínio clínico na residência médica do IFF [Dissertação de Mestrado]. Rio de Janeiro: Instituto Fernandes Figueira, Fundação Oswaldo Cruz; 1996.

20. Winograd T, Flores F. Undestanding computers and cognition: a new foundation for design. Norwood: Ablex; 1986.

21. Cardoso MHCA. A herança arcaica de um modelo. História, medicina...e a síndrome de Down [Tese de Doutorado]. Rio de Janeiro: Instituto Fernandes Figueira, Fundação Oswaldo Cruz; 2000.

22. Hunter KM. Doctor's stories. The narrative structure of medical knowledge. Princeton: Princeton University Press; 1991. 
23. Epstein J. Altered conditions. Disease, medicine, and storytelling. New York: Routledge; 1995.

24. Foucault M. Microfísica do poder. Rio de Janeiro: Edições Graal; 1990.

25. Ávila MB. Direitos sexuais e reprodutivos: desafios para as políticas de saúde. Cad Saúde Pública 2003; 19 Suppl 2:465-9.

26. Lupton D. Foucault and the medicalisation critique. In: Petersen A, Burton R, editors. Foucault. Health and medicine. London/New York: Routledge; 1997. p. 94-110.

27. Keller EF. The gender/science system: or, is sex to gender as nature is to science? In: Biagioli M, editor. The science studies reader. New York: Routledge; 1999. p. 234-43.
28. Smith D. Diagnosis goes low tech. New York Times 2003. http://www.nytimes.com (acessado em 11/Out/2003).

29. Mehry EE. Saúde: cartografia do trabalho vivo. São Paulo: Editora Hucitec; 2002.

30. Booth WC. The ethics of medicine, as revealed in literature. In: Charon R, Montello M, editors. Stories matter. The role of narrative in medical ethics. New York: Routledge; 2002. p. 10-20.

31. Dumit J, Davis-Floyd R. Introduction. Cyborg babies. Children of the third millennium. In: Dumit J, Davis-Floyd R, editors. Cyborg babies. From techno-sex to techno-tots. New York/London: Routledge; 1998. p. 1-18.

Recebido em 20/Mai/2005

Versão final reapresentada em 24/Ago/2005 Aprovado em 04/Out/2005 